\title{
PERANCANGAN KNOWLEDGE MANAGEMENT SYSTEM BERBASIS WEB PADA TENAGA KEPENDIDKAN FAKULTAS TEKNIK UNIVERSITAS PGRI MADIUN
}

\author{
Sri Anardani*1, Slamet Riyanto², Dimas Setiawan ${ }^{3}$ \\ 1,2,3 Fakultas Teknik Universitas PGRI Madiun \\ Email: 19anardani@unipma.ac.id , ${ }^{2}$ selamat@unipma.ac.id, ${ }^{3}$ Dimas.Setiawan@unipma.ac.id \\ *Penulis Korespondensi
}

(Naskah masuk: 10 Februari 2020, diterima untuk diterbitkan: 01 Februari 2021)

\begin{abstract}
Abstrak
Tenaga kependidikan merupakan barisan terdepan pelayanan administrasi yang dituntut mampu beradaptasi dengan cepat terhadap perubahan di lingkungan kerja. Secara rutin Universitas PGRI Madiun melaksanakan kegiatan mutasi, rotasi dan pensiun terhadap tenaga kependidikan. Hal ini berdampak pada banyaknya pengetahuan yang hilang karena dibawa oleh tenaga kependidikan yang dipindah atau sudah pensiun. Penelitian ini bertujuan menganalisa perancangan Knowledge Management System berbasis web untuk mengolah data pengetahuan tenaga kependidikan di Fakultas Teknik Universitas PGRI Madiun. Metodologi yang digunakan pada penelitian ini merujuk pada kerangka kerja 10-Step Knowledge Management Roadmap milik Amrit Tiwana. Metode perancangan sistem menggunakan pendekatan berorientasi objek dengan tools UML (Unified Modelling Languange). Untuk pengujian kebutuhan fungsioanl sistem menggunakan metode FGD dengan responden tenaga kependidikan fakultas teknik. Penelitian ini menghasilkan dokumen rancangan aplikasi KMS yang dapat memberikan rekomendasi bagi lembaga untuk membangun aplikasi KMS di masa depan.
\end{abstract}

Kata kunci: knowledge management system, 10-step KM roadmap, UML

\section{WEB-BASED KNOWLEDGE MANAGEMENT SYSTEM DESIGN ON THE STAFF OF THE FACULTY OF ENGINEERING PGRI MADIUN UNIVERSITY}

\begin{abstract}
Educational staff are at the forefront of the administration which is demanded to be able to quickly change in the work environment. The PGRI Madiun University routinely carries out mutation, rotation and retirement activities for educational staff. This has an impact on the amount of knowledge lost because it is carried by the transferred or retired teaching staff. This study aims to analyze the design of a web-based Knowledge Management System to process the knowledge of educational staff in the Faculty of Engineering, University of PGRI Madiun. The methodology used in this study refers to Amrit Tiwana's 10-Step Knowledge Management Roadmap. The system design method uses object-oriented approach with UML (Unified Modeling Language) tools. To test the system functional requirements requirements using FGD method with engineering faculty respondent. This research produces a KMS application design document that can provide recommendations for institutions to build KMS applications in the future.
\end{abstract}

Keywords: knowledge management system, 10-step KM roadmap, UML

\section{PENDAHULUAN}

Tenaga kependidikan pada Perguruan Tinggi merupakan komponen penting yang perlu mendapatkan perhatian. Tenaga kependidikan merupakan barisan depan pelayanan administrasi yang dituntut mampu beradaptasi dengan cepat terhadap perubahan di lingkungan kerja. Fakultas Teknik Universitas PGRI Madiun terus melakukan upaya perbaikan kinerja untuk menghadapi persaingan. Salah satu upaya yang dilakukan adalah peningkatan kinerja tenaga kependidikan.

Secara rutin Universitas PGRI Madiun melaksanakan kegiatan mutasi, rotasi dan pensiun terhadap tenaga kependidikan di fakultas teknik. Kegiatan ini dilaksanakan minimal 2 tahun sekali. Hal ini berdampak pada banyaknya pengetahuan yang hilang karena dibawa oleh tenaga kependidikan yang dipindah atau sudah pensiun. Knowledge yang bersifat individu akan ikut terbawa oleh tenaga 
kependidikan yang pergi. Beberapa contoh knowledge yang hilang misalnya adalah knowledge yang dimiliki oleh staff tata usaha prodi seperti membuat jadwal perkuliahan program studi, membuat jadwal pelaksanaan ujian skripsi. Tenaga kependidikan dituntut untuk cepat beradaptasi pada lingkungan baru, sementara banyaknya knowledge yang hilang dapat menimbulkan kesalahankesalahan yang berulang dilakukan.,

Banyak knowledge sumber daya manusia pada fakultas teknik Universitas PGRI Madiun yang tergantung pada tenaga kependidikan secara personal, namun apabila knowledge setiap tenaga kependidikan ini didokumentasikan dengan baik maka dapat dimanfaatkan oleh seluruh karyawan agar unggul dalam menghadapi persaingan. Knowledge yang sangat luas dan kompleks dapat dikelola dengan memanfaatkan Knowledge Management System berbasis teknologi informasi (Wijaya, 2017)

Seperti pada penelitian Choirunsyah dan Heryanto, 2019 menunjukkan bahwa peningkatan jumlah tenaga kependidikan berdampak pada timbulnya aktivitas mutasi, rotasi dan kenaikan jabatan. Aktivitas ini menimbulkan masalah kehilangan tenaga senior yang membawa keahliannya sehingga knowledge yang dimiliki senior tidak terdistribusi dengan baik kepada karyawan baru.

Menurut Sari dan Tania, 2014 dalam penelitiannya menyatakan bahwa tujuan dari mendokumentasikan knowledge penting yang menunjang kegiatan fakultas adalah agar knowledge yang dimiliki tenaga kependidikan dapat di sharing kepada karyawan lain sehingga tercipat forum untuk mendiskusikan dan mendistribusikan permasalahan.

Pada prinsipnya Knowledge Management System bertujuan untuk memperbaiki komunikasi sehingga dapat meningkatkan kualitas Sumber Daya Manusia dan menumbuhkan budaya sharing knowledge antar individu didalam suatu organisasi (Akbar, 2018).

Berdasarkan hasil uraian diatas untuk mengatasi permasalahan fakultas teknik terkait knowledge tenaga kependidikan maka perlu adanya suatu sistem yang mampu mengelola dan mendistribusikan knowledge kepada tenaga kependidikan sehingga knowledge yang dimiliki tenaga kependidikan tidak hilang dan kesalahankesalahan dapat diminimalkan.

Knowledge Management adalah salah cara untuk membiasakan berkomunikasi dan berbagi pengetahuan antar anggota organisasi sehingga setiap anggota mendapatkan kesempatan belajar (Sari dan Tania, 2014). Menjaga knowledge organisasi adalah salah satu cara untuk mempertahankan nilai-nilai organisasi, sehingga kualitas kinerja anggota organisasi dapat dipertahankan untuk menghadapi persaingan bisnis. Sumber knowledge yang terstruktur dengan baik akan memudahkan perusahaan beradapatasi dengan perubahan lingkungan bisnis sehingga produktivitas perusahaan meningkat (Octaria dan Ermatita,2017)

Sasaran umum kegiatan mengembangkan Knowledge Management System menurut Davenport et al dalam Alusi, 2013adalah menciptakan knowledge, menangkap knowledge baru, menjaring knowledge, menyimpan knowledge, mengolah knowledge, dan menyebarluaskan knowledge.

Pemanfaatan Knowledge Management System (KMS) memberikan dampak positif bagi kelangsungan bisnis organisasi, hal ini terjadi karena KMS merupakan cara yang efektif untuk menerjemahkan pengalaman kerja secara berkelanjutan dalam bentuk pengetahuan. KMS juga mampu mentransfer pengetahuan organisasi secara lintas waktu dan lintas ruang.

Penelitian ini bertujuan menganalisa perancangan Knowledge Management System berbasis web untuk mengolah data pengetahuan tenaga kependidikan di Fakultas Teknik Universitas PGRI Madiun. Metodologi yang digunakan pada penelitian ini merujuk pada kerangka kerja 10-Step Knowledge Management Roadmap milik Amrit Tiwana. Metodologi 10-Step Knowledge Management Roadmap memiliki kelebihan dibanding dengan metode lain adalah mampu mencatat semua aktivitas prose bisnis sesuai konteks perencanaan (Herlinda,dkk, 2017). Untuk proses perancangan menggunakan pendekatan berorientasi objek dengan tools UML (Unified Modelling Languange). Hasil dari penelitian ini adalah sebuah cetak biru perancangan sistem yang akan menjadi rekomendasi bagi lembaga untuk proses pengembangan Knowledge Management System di masa yang akan datang.

\section{METODE PENELITIAN}

Pengetahuan adalah satu-satunya sumber daya yang tidak dapat dengan mudah disalin. Manajemen pengetahuan merupakan kegiatan yang sangat kompleks dan akan menimbulkan dampak bisnis apabila tidak direncanakan dengan baik. The 10-Step Knowledge Management Roadmap akan memandu kita menciptakan strategi pengelolaan pengetahuan berbasis bisnis melalui perangkat lunak

Metode The 10-Step Knowledge Management Roadmap merupakan langkah strategik milik Tiwana pada proses penerapan Knowledge Management dalam suatu organisasi (Andriansyah, 2015). Metode ini terdiri atas 4 fase yaitu fase evaluasi infrastruktur, fase analisis, desain dan pengembangan KM, fase penyebaran, fase evaluasi.

Kegiatan yang dilakukan pada fase evaluasi infrastruktur adalah mengevaluasi infrastruktur yang berjalan serta culture pengetahuan yang diterapkan saat ini. Fase analisis, desain dan pengembangan merupakan fase merancang arsitektur dan dokumen 
cetak biru Knowledge Management System. Fase yang ketiga yaitu penyebaran merupakan proses penyebaran Knowledge Management System yang telah dibangun pada tahap sebelumnya. Fase evaluasi adalah fase terakhir yang dilaksanakan, yaitu mengukur tingkat keberhasilan bisnis atas penerapan Knowledge Management System yang telah dibangun. Metode 10 langkah Tiwana seperti pada Gambar 1 ini kedepannya akan sangat membantu proses pengembangan dan implementasi Knowledge Management System.

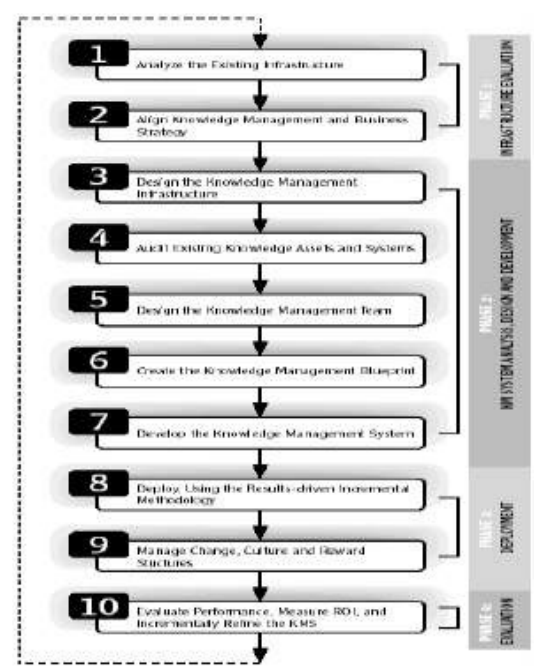

Gambar 1. The 10 Step Knowledge

Management Roadmap (Tiwana dalam Adriansyah, 2015)

Metode pengembangan sistem yang digunakan pada penelitian ini adalah mengadopsi The 10-Step Knowledge ManagementRoadmap yang digagas oleh Amrit Tiwana. Pada penelitian ini fase The 10Step Knowledge Management Roadmap dibatasi hanya pada fase 1 dan fase 2 , yaitu fase evaluasi infrastruktur dan fase analisi serta desain Knowledge Management System.

Pada Fase pertama tahap kegiatan yang dilakukan adalah menganalisa kondisi infrastruktur dan budaya knowledge sharing yang sedang berjalan saat ini. Pada tahap ini fokus pada kerangka kerja teknik manajemen pengetahuan serta komponenkomponen pembentuknya. Kemudian tahap berikutnya adalah menganalisa proses bisnis dan knowledge yang dihasilkan dari proses bisnis tersebut. Strategi bisnis dianalisa menggunakan metode SWOT berbasis knowledge yang bertujuan untuk mengetahui gap knowledge yang terjadi saat ini.

Fase kedua tahapan kegiatan yang dilakukan adalah pertama membuat desain arsitektur Knowledge Management System dengan memilih komponen infrastruktur dan mengintegrasikan komponen tersebut untuk menjadi model sistem Knowledge Management. Berikutnya membuat perancangan fitur sistem KMS dengan pemodelan UML. Permodelan UML merupakan sistem perancangan yang bekerja dalam bentuk Object Oriented Analysis and Design (OOAD) dengan bahasa yang konsisten menentukan, visualisasi, konstruksi, dan dokumentasikomponen-komponen yang terdapat dalam sistem perangkat lunak (Suryati, 2015).

UML merupakan salah satu metode pendekatan untuk mengembangkan sistem perangkat lunak yang responsif terhadap proses bisnis yang cenderung berubah (Dewati, dkk, 2019). UML adalah alat yang digunakan untuk membangun perangkat lunak yang meliputi konsep proses bisnis, penulisan kelas, perancangan database, dan komponen-komponen yang diperlukan dalam sistem perangkat lunak.

Dengan metode UML pengembang cukup menggunakan satu tools untuk proses analisa hingga perancangan sistem perangkat lunak..

Kegiatan kedua adalah mengidentifikasi aset knowledge, siapa yang memegang peranan penting atas knowledge tersebut. Langkah ketiga adalah menyusun blue print Knowledge Management System. Langkah ini berfungsi untuk mengintegrasikan seluruh kegiatan sebelumnya sehingga berorientasi pada strategi yang dapat menjadi rekomendasi bagi pemangku keputusan di masa depan.

Proses pengumpulan data dilakukan dengan beberapa teknik yaitu wawancara dengan narasumber, kegiatan observasi melalui pengamatan terhadap aktivitas-aktivitas knowledge management yang sedang berjalan di fakultas teknik dan studi pustaka dengan mempelajari sumber pustaka untuk menambah wawasan terkait management knowledge sistem

Keseluruhan langkah-langkah kegiatan dalam penelitian ini dapat digambarkan seperti pada gambar 2 sebagai berikut:

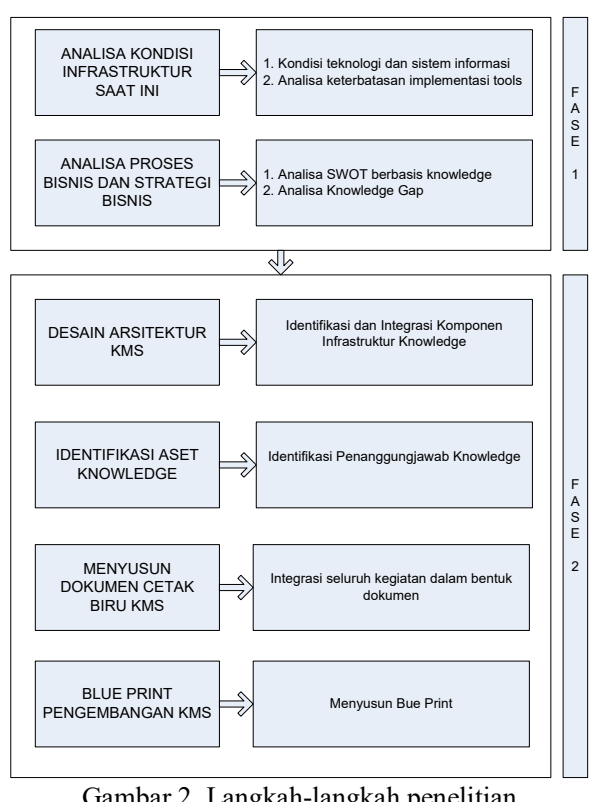

Gambar 2. Langkah-langkah penelitian 


\section{PEMBAHASAN}

\subsection{Analisa Kondisi Infrastruktur Teknologi}

Langkah menganalisa kondisi infrasruktur teknologi dilakukan dengan tujuan untuk mengevaluasi seberapa baik infrastruktur yang telah dijalankan saat ini. Hasil analisa dapat digunakan untuk membantu mengambil keputusan apakah sistem yang telah berjalan ini dapat ditingkatkan atau diganti dengan sistem yang baru.

Kondisi Infrastruktur teknologi yang diamati di Fakultas Teknik adalah terkait dengan sistem informasi dan jaringan komputer. Saat ini pengelolaan data akademik, kepegawaian dan keuangan dikelola melalui sistem informasi manajemen terpusat. Sistem dapat diperbaharui informasinya dari berbagai lokasi. Gambaran kondisi infrastruktur saat ini dapat dilihat pada gambar 3 berikut ini

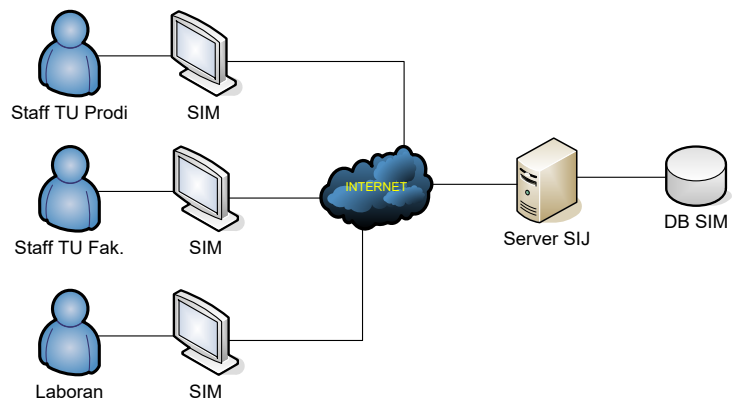

Gambar 3. Kondisi Infrastruktur Saat Ini

Tenaga kependidikan mendapatkan hak akses untuk mengelola data di Sistem Informasi Manajemen sesuai deskripsi tugas dari masingmasing Tenaga Kependidikan. Apabila ada fitur baru terkait pengelolaan data lembaga melalui biro Sistem Informasi dan Jaringan akan memberikan pelatihan kepada tenaga kependidikan yang terlibat. Masalah akan timbul apabila ada proses mutasi atau ada rekrutmen tenaga baru, knowledge yang dimilki oleh tenaga sebelumnya yang telah mendapatkan pelatihan akan ikut terbawa oleh yang bersangkutan. Hal ini menyebabkan proses pengelolaan data menjadi terhambat dan proses bisnis pelayanan administrasi kepada pihak terkait menimbulkan rasa tidak puas. Pada sistem yang berjalan saat ini tidak ada pengelolaan knowledge sharing tenaga kependidikan yang menunjang kinerja tenaga kependidikan.

\subsection{Analisa Proses dan Strategi Bisnis}

Pada tahap ini dilakukan pemetaan knowledge berdasarkan proses bisnis yang dijalankan oleh fakultas. Berdasarkan analisa pemetaan proses bisnis pada gambar 2 dapat di identifikasi bahwa terdapat 6 proses bisnis yang dijalankan di Fakultas Teknik. Keenam proses bisnis tersebut adalah pengelolaan data administrasi akademik, pengelolaan data SDM, pengelolaan data penelitian dan abdimas, pengelolaan data keuangan, pengelolaan data kemahasiswaan dan pengelolaan data sapras. Dari 6 proses bisnis tersebut dapat diketahui deskripsi data dan dokumen yang ada saat ini. Adapun pemetaan proses bisnis dapat digambarkan pada gambar 4 sebagai berikut:

\begin{tabular}{|c|c|}
\hline Proses Bisnis & $\begin{array}{l}\text { Identifikasi Data dan } \\
\text { Dokumen }\end{array}$ \\
\hline $\begin{array}{l}\text { Pengelolaan Data } \\
\text { Administrasi Akademik }\end{array}$ & $\begin{array}{l}\text { data mahasiswa, data mahasiswa } \\
\text { teryudisium, data RPS, data } \\
\text { silabus, jurnal dan presensi } \\
\text { perkuliahan, jadwal perkuliahan, } \\
\text { jadwal ujian skripsi, jadwal seminar }\end{array}$ \\
\hline Pengelolaan Data SDM & $\begin{array}{l}\text { Laporan data kehadiran dosen dan } \\
\text { tenaga kependidikan, laporan } \\
\text { kebutuhan tenaga dosen dan } \\
\text { tenaga kependidikan }\end{array}$ \\
\hline $\begin{array}{l}\text { Pengelolaan Data Penelitian } \\
\text { dan Abdimas }\end{array}$ & $\begin{array}{l}\text { Data penelitian, data abdimas, } \\
\text { laporan penelitain\&abdimas }\end{array}$ \\
\hline Pengelolaan Data Keuangan & $\begin{array}{l}\text { Data biaya praktikum, laporan LPJ } \\
\text { keuangan }\end{array}$ \\
\hline $\begin{array}{l}\text { Pengelolaan Data } \\
\text { Kemahasiswaan }\end{array}$ & Data beasiswa, data alumni \\
\hline Pengelolaan Data Sapras & Data laporan kondisi sarpras \\
\hline
\end{tabular}

Langkah berikutnya adalah menganalisa kondisi strategi bisnis fakultas teknik berbasis knowledge menggunakan metode SWOT sebagai berikut:

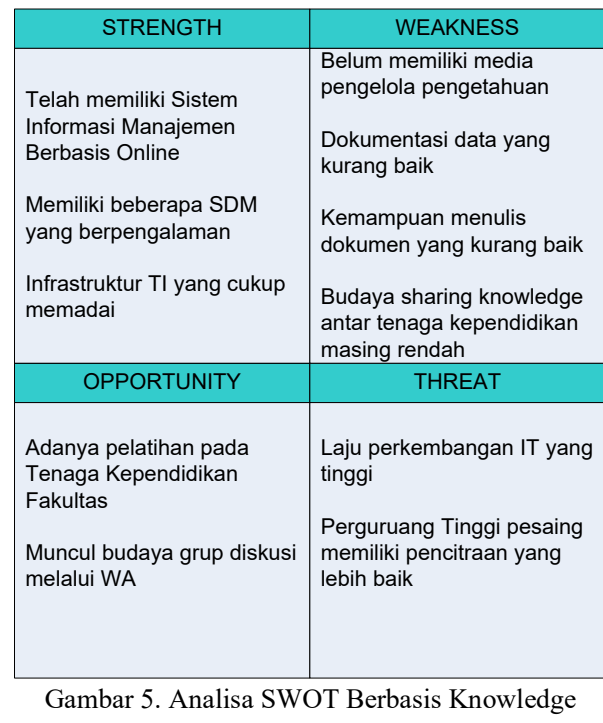

Berdasarkan analisa SWOT pada gambar 5 diatas maka dapat disimpulkan bahwa kelemahan yang dimilki oleh Fakultas Teknik dapat diatasi dengan kekuatan yang dimiliki serta memanfaatkan peluang yang ada. Berdasarkan kelemahan yang dimiliki maka strategi yang direkomendasikan adalah dengan membangun Knowledge Management System yang dimiliki oleh tenaga kependidikan agar data knowledge dapat terdokumentasi dengan baik. 


\subsection{Desain Arsitektur Knowledge Management} System

Membuat perancangan arsitektur adalah langkah pertama yang dilakukan. Proses ini bertujuan untuk memberikan gambaran bagaimana sistem dibangun sebagai satu kesatuan komponen yang saling berhubungan. Usulan desain arsitektur KMS disusun dengan memperhatikan kebutuhan informasi dan teknologi yang akan diterapkan yaitu berbasis website.

Website merupakan kumpulan dari halamanhalaman yang ditulis dalam format HTML yang bisa diakses melalui World Wide Web (www) di internet (Trimarsiah dan Arafat, 2017).

Halaman dari website akan diakses melalui HTTP, kemudian informasi ditampilkan kepada pengguna melalui web browser. Informasi di dalam web dapat berbentuk teks, gambar, video dan suara yang dipresentasikan dalam bentuk hypertext.

Layanan website hanya dapat dipakai oleh pengguna komputer yang terhubung ke internet. Web memudahkan pengguna komputer berinteraksi dengan pengguna internet lainnya serta dapat menelusuri informasi (Wulandari, 2018).

Usulan desain arsitektur KMS ini diharapkan dapat membantu proses pembangunan sistem kedepannya. Pada arsitektur dapat dilihat bahwa tenaga kependidikan dapat berbagi pengetahuan dalam satu wadah sehingga proses penyebaran pengetahuan dapat dilakukan setia saat dimanapun selama dalam lingkup jaringan sistem KMS. Pengguna pada sistem terdiri atas Administrator sistem yang memiliki tugas mengatur, memelihara dan mengolah pemberian hak akses modul-modul pengetahuan yang ada dalam sistem. Pengguna sistem kedua adalah tenaga kependidikan yang bertugas untuk memasukkan data dokumen, mencari dan mempelajari knowledge yang ada di sistem yang dibutuhkan dalam pengelolaan data fakultas. Pengguna terakhir adalah pimpinan yang memiliki hak akses untuk memasukkan data SOP fakultas. Pada Gambar 6 dibawah ini merupakan arsitektur KMS pada tenaga kependidikan di Fakultas Teknik.

\subsection{Penyusunan Blue Print Knowledge Management System}

Dokumen blue print pengembangan KMS di fakultas teknik berisi integrasi keseluruhan kegiatan yang dibuat dalam bentuk dokumen. Dokumen memuat analisa kebutuhan sistem, rancangan arsitektur sistem dan rancangan sistem KMS.

Untuk analisa perancangan fungsional sistem menggunakan UML tools berupa use case diagram seperti tampak pada gambar 7 .

Gambaran struktur sistem dirancang melalui class diagram yang merepresentasikan hubungan antara kelas atau obyek yang didalamnya memuat atribut dan metode. Adapun class diagram dari KMS Fakultas Teknik yang akan dikembangkan dapat dilihat pada gambar 8 .

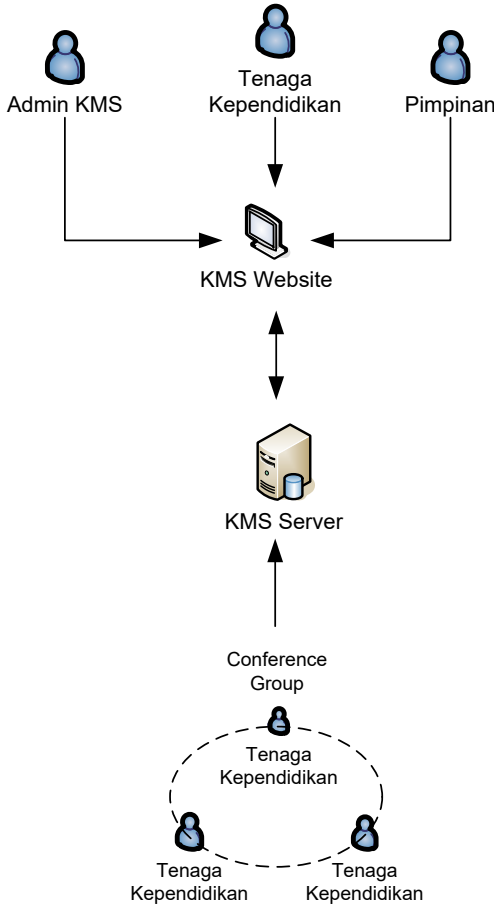

Gambar 6. Desain Arsitektur KMS Fakultas Teknik

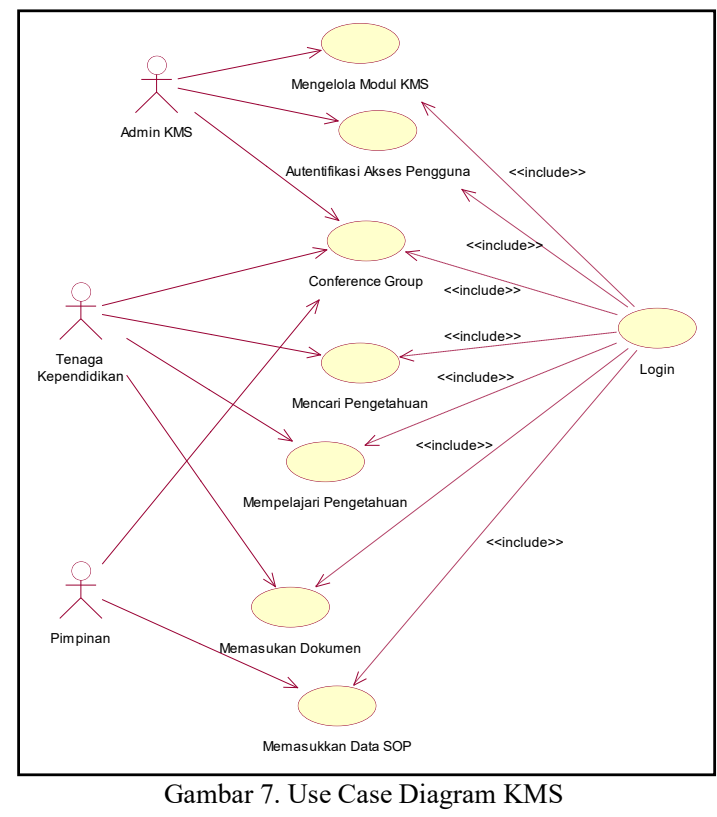

Proses pengujian terhadap hasil analisa perancangan yang tertuang di dokumen blue print dilakukan dengan menggunakan metode FGD (Focus Group Discussion) yaitu dengan mengundang tenaga kependidikan di lingkup Fakultas Teknik untuk mevalidasi apakah usulan rancangan sistem tersebut sudah sesuai dengan yang dibutuhkan oleh tenaga kependidikan. Adapun jumlah responden yang diundang ada 6 orang. Adapun rekapitulasi hasil validasi seperti pada Tabel 1. 


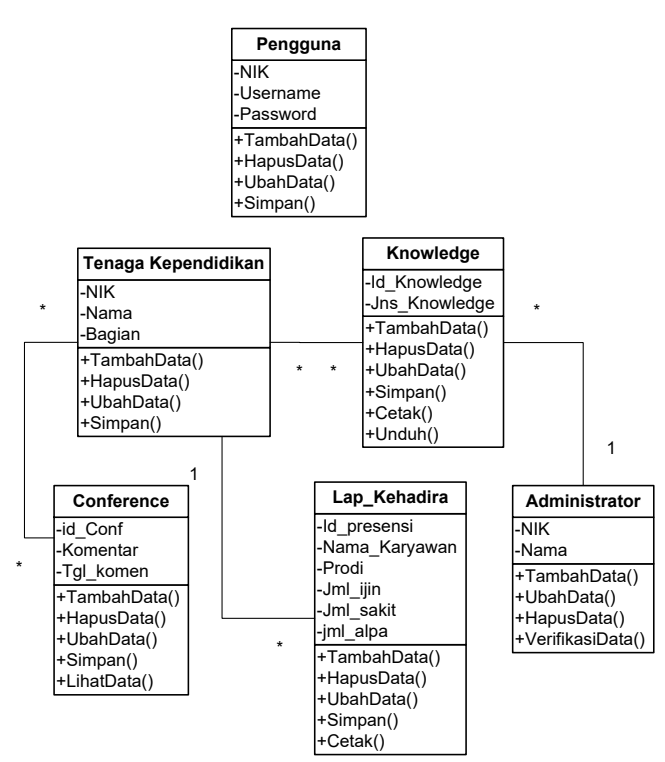

Gambar 8. Class Diagram KMS Fakultas Teknik

Tabel 1. Rekapitulasi FGD Responden

\begin{tabular}{|c|c|c|c|c|}
\hline \multirow[t]{2}{*}{ No } & \multirow{2}{*}{$\begin{array}{l}\text { Analisa } \\
\text { Kebutuhan }\end{array}$} & \multicolumn{2}{|c|}{ Jawaban } & \multirow{2}{*}{$\begin{array}{l}\text { Prosentase } \\
\text { Diterima }\end{array}$} \\
\hline & & Diterima & Ditolak & \\
\hline 1 & $\begin{array}{l}\text { Mengelola modul } \\
\text { KMS }\end{array}$ & 6 & - & $100 \%$ \\
\hline 2 & $\begin{array}{l}\text { Autentifikasi } \\
\text { Akses Pengguna }\end{array}$ & 6 & - & $100 \%$ \\
\hline 3 & $\begin{array}{l}\text { Conference } \\
\text { Group }\end{array}$ & 6 & - & $100 \%$ \\
\hline 4 & $\begin{array}{l}\text { Mencari } \\
\text { Pengetahuan }\end{array}$ & 6 & - & $100 \%$ \\
\hline 5 & $\begin{array}{l}\text { Mempelajari } \\
\text { Pengetahuan }\end{array}$ & 6 & - & $100 \%$ \\
\hline 6 & $\begin{array}{l}\text { Memasukkan } \\
\text { Dokumen }\end{array}$ & 6 & - & $100 \%$ \\
\hline 7 & $\begin{array}{l}\text { Memasukkan } \\
\text { Data SOP }\end{array}$ & 5 & 1 & $83 \%$ \\
\hline $\begin{array}{l}\text { dar } \\
\text { yar } \\
\text { Ad } \\
\text { ads }\end{array}$ & $\begin{array}{l}\text { Berdasarkan ha } \\
\text { t disimpulkan b } \\
\text { telah dirancang } \\
1 \text { responden yar } \\
\text { ya data SOP did }\end{array}$ & $\begin{array}{l}\text { rekapit } \\
\text { iwa ana } \\
\text { ata-rata } \\
\text { tidak } m \\
\text { am siste }\end{array}$ & $\begin{array}{l}\text { asi respo } \\
\text { a kebut } \\
\text { sponder } \\
\text { erima te }\end{array}$ & $\begin{array}{l}\text { en, maka } \\
\text { an sistem } \\
\text { henerima. } \\
\text { ait usulan }\end{array}$ \\
\hline
\end{tabular}

\section{KESIMPULAN}

Kesimpulan dari hasil penelitian ini telah berhasil menyusun dokumen analisa kebutuhan sistem, rancangan arsitektur sistem dan rancangan struktur sistem pengembangan aplikasi KMS di Fakultas Teknik, sehingga dapat memberikan rekomendasi bagi lembaga untuk membangun aplikasi KMS di masa depan.

Berdasarkan hasil pengujian dengan metode FGD, sejumlah 6 responden rata-rata menyatakan menerima usulan analisa kebutuhan fungsional sistem yang akan digunakan untuk pengembangan sistem KMS di Fakultas Teknik di masa depan.

Kerangka kerja dengan Metode The 10-Step Knowledge Management Roadmapmilik Tiwana dapat diterapkan pada Fakultas Teknik UNIPMA. Pelaksanaan pembangunan aplikasi KMS sebaiknya mengacu pada Blueprint yang telah disusun sehingga dapat digunakan sesuai dengan yang diharapkan.

\section{DAFTAR PUSTAKA}

AKBAR, Y. 2018. Knowledge Management System Pada Biro Administrasi Akademik Akademi Pariwista Nusantara.Jurnal String, 3(1), 87-97.

ADRIANSYAH, D. 2015. Perancangan Prototype Aplikasi KnowledgeManagement Untuk Mendukung Proses Knowledge Sharing Pada PT. Prima Cipta Mandiri Sejati.Paradigma, 17(2), 1-13.

ALUSI, F. 2013. Kajian Pengembangan Knowledge Management System (KMS) Untuk Litbang Kedirgantaraan Pada Lembaga Penerbangan Dan Antariksa Nasional (LAPAN).Berita Dirgantara, 14(1), 17-25

CHOIRUNSYAH, A. F. \& HERYANTO, H. 2019.Perancangan Knowledge Management System Pada Tenaga Kependidikan Di Perguruan Tinggi. Infomatek, 21(1), 1-14.

DEWATI, R. C., AKNURANDA, I. \& PUTRA, N. H. W. 2019. Analisis dan Perancangan Sistem Informasi Pengarsipan Dokumen Dengan Pendekatan Berorientasi Objek (Studi Kasus : Dinas Sekretariat Dewan, Pemerintahan Kota Batu).Jurnal Pengembangan Teknologi Informasi dan Ilmu Komputer, 3(5), 5140-5146.

HERLINDA, MUTIA, I., \& ATIKAH. 2017. Perancangan Knowledge Management System (KMS) Kurikulum 2013 Sekolah Menengah Atas Negeri Di Jakarta Selatan. Seminar Nasional TEKNOKA, 2(2), 1-7.

OCTARIA, O. \& ERMATITA. 2018. Analisis Knowledge Management Systemdengan Metode Inukshuk.Annual Research Seminar Computer Science and ICT, 3(1), 35-38.

SARI, K. W. \& TANIA, D. K. 2014. Penerapan Knowledge Management System (KMS) Berbasis WebStudi Kasus Bagian Teknisi dan Jaringan Fakultas Ilmu Komputer Universitas Sriwijaya.Jurnal Sistem Informasi, 6(2), 681-688

SURYATI, P. 2015. Analisis Dan Perancangan Berorientasi Obyek Sistem Penjadwalan Koas.Jurnal Teknologi Informasi, 10(28), 1-13.

TRIMARSIAH, Y. \& ARAFAT, M. 2019. Analisis Dan Perancangan Website Sebagai Sarana Informasi Pada Lembaga Bahasa Kewirausahaan Dan Komputer Akmi Baturaja.Jurnal Ilmiah Matrik, 19(1), 1-10. 
WULANDARI. 2018. Perancangan Website Tk Pertiwi Dharmawanita Kecamatan Kubung Kabupaten Solok.Jurnal Saiko, 1(1), 17-22

WIJAYA, E. A. 2017. Knowledge Management System Model Pada Forum Diskusi Petani Buah Naga Menggunakan CMS phpBB.Jurnal Teknologi Informasi dan Ilmu Komputer (JTIIK), 4(1), 44-51. 
Halaman ini sengaja dikosongkan 